
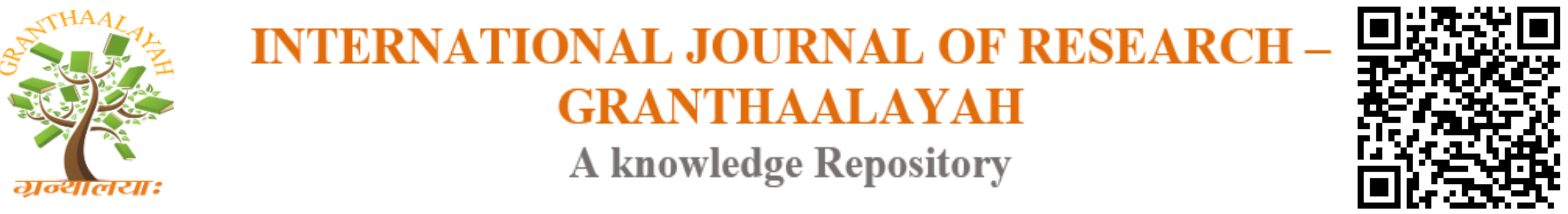

Science

\title{
EXPERIMENTAL STUDY ON THE STRENGTH DEVELOPMENT ON CONCRETE BY PARTIAL REPLACEMENT OF COARSE AGGREGATES BY WASTED TRUCK TYRE PIECES
}

\author{
Raghavendra Prasad Havanje Dinakar ${ }^{1}$, Pavan P S ${ }^{2}$, Vishal Gadgihalli ${ }^{3}$, Ramesh C P ${ }^{4}$ \\ ${ }^{* 1}$ Research Assistant, Department of civil engineering, Jain University, Bangalore, India \\ ${ }^{2}$ Assistant Professor, Department of civil engineering, Jain University, Bangalore, India \\ ${ }^{3}$ UG Student, Department of civil engineering, Jain University, Bangalore, India \\ ${ }^{4}$ Associate Professor, Department of civil engineering, Jain University, Bangalore, India
}

\begin{abstract}
Wasted Truck Tyres can be used as an alternative for concrete coarse aggregate. The used tyres of truck are properly cutted and different ratios can be added to concrete blocks. The main components of modern tyres are synthetic rubber, natural rubber, fabric and wire, along with carbon black and chemical compounds. In the present paper, Truck Tyres are used as conventional coarse aggregate in concrete for high strength (M50 Grade) concrete for every incremental of $25 \%$ replacement up to $100 \%$ is done. Slump cone test, Vee-Bee consistometer test and Compaction factor test are conducted to find freshness of concrete. The concrete is casted in cubes to harden it, tests such as compressive strength, cylinders for split tensile strength and prisms for flexural strength for 7days, 14days and 28days curing are done. The results obtained are compared with conventional coarse aggregate ( $0 \%$ replacement) concrete.
\end{abstract}

Keywords: Alternative Materials; Tyre Pieces; Concrete Properties and Replacement of Coarse Aggregates.

Cite This Article: Raghavendra Prasad Havanje Dinakar, Pavan P S, Vishal Gadgihalli, Ramesh C P. (2017). "EXPERIMENTAL STUDY ON THE STRENGTH DEVELOPMENT ON CONCRETE BY PARTIAL REPLACEMENT OF COARSE AGGREGATES BY WASTED TRUCK TYRE PIECES.” International Journal of Research - Granthaalayah, 5(11), 414-424. https://doi.org/10.29121/granthaalayah.v5.i11.2017.2375.

\section{Introduction}

Concrete is third most important resource used by humans after air and water. The most commonly used coarse aggregate is crushed rock ballast. The manufacture of coarse aggregate by crushing rock ballast causes environmental pollution. Now a day there is a scarcity of coarse aggregate due to increase in cost and infrastructural growth. This mainly directed towards exploring the possibilities of making effective use of alternative materials. The rubber aggregates 
were used as an alternative of coarse aggregate by partial replacement and the effects of strength and workability in concrete were investigated.

As the waste rubber from tyres is hazardous to environment if we burnt or dispose it to air, soil. Water respectively due to hydrocarbons and noxious emission, these can be used as coarse aggregates as partial replacement which effects on strength and workability of concrete.

This type of replacement and recycling can be an alternative solution that must be focused by government. Currently only about $4.5 \%$ of tyres are recycled in civil engineering applicants.

\subsection{Rubberized concrete}

As rubber from chips of waste rubber is mixed as coarse aggregates in different proportion can improve concrete qualities such as low unit weight, high resistance to abrasion, improve shock and vibration absorbing characteristics. This also results in resilience, durability and elasticity.

The concrete mix M30 was designed as per IS: 10262-2004 Using 10\%, 25\% and 50\% replacement of natural aggregate by rubber aggregates. And also for M15 grade of concrete, nominal mix design was carried out using $10 \%, 25 \%$ and $50 \%$ replacement of natural aggregate by rubber aggregates. The workability of fresh concrete was studied but concrete cubes are cast and allowed to cure in water after 24-hrs setting. These cubes are tested for 7 days and 28 days strengths.

\section{Testing of Materials}

It is necessary to test the ingredient materials before using concrete use in cement concrete to suit the requirements of various IS codes specifications.

\subsection{Test on Portland Cement}

Brand: Vasavadatta 43 grade (OPC)

The various tests conducted on cements and the results obtained are as shown in the table 3.1.1. The tests are conducted as per IS: 4031(part4, 5)-1988(6).

\begin{tabular}{|c|c|c|c|}
\hline $\begin{array}{l}\text { Serial } \\
\text { No }\end{array}$ & Test conducted & Results & $\begin{array}{l}\text { Specifications as per IS } \\
\text { 8112-1989. }\end{array}$ \\
\hline 1 & Standard Consistency & $32 \%$ & \\
\hline 2 & $\begin{array}{l}\text { Initial setting time of cement } \\
\text { Final setting time of cement }\end{array}$ & $\begin{array}{l}40 \mathrm{~min} \\
3 \mathrm{hrs} 45 \mathrm{~min}\end{array}$ & $\begin{array}{l}\text { Not less than } 30 \mathrm{~min} \\
\text { Not greater than } 10 \mathrm{hrs}\end{array}$ \\
\hline 3 & Specific gravity of cement. & 2.9 & \\
\hline 4 & $\begin{array}{l}\text { Compressive strength at } \\
3 \text { days } \\
7 \text { days }\end{array}$ & $\begin{array}{l}29.24 \mathrm{~N} / \mathrm{mm} 2 \\
38.5 . \mathrm{N} / \mathrm{mm} 2\end{array}$ & $\begin{array}{l}\text { Not less than } \\
27 \mathrm{~N} / \mathrm{mm}^{2} \\
37 \mathrm{~N} / \mathrm{mm}^{2}\end{array}$ \\
\hline
\end{tabular}

Note: Cement used is mainly Vasavadatta 43 Grade confirms to specification of IS 8112-1989 for the above tests. 


\subsection{Tests on Coarse Aggregate (20mm Downsize Aggregate)}

The different tests conducted on coarse aggregate and the results obtained are as follows. The tests are conducted as per IS: 2386(part, 3)-1963(7).

\section{Sieve analysis}

The results of sieve analysis conducted on coarse aggregate are as shown in the Table 3.2.1.

$\begin{array}{cccccc}\begin{array}{c}\text { Sl. } \\ \text { No }\end{array} & \begin{array}{c}\text { IS Sieves } \\ (\mathbf{m m})\end{array} & \begin{array}{c}\text { Weight } \\ \text { retained W(gm) }\end{array} & \begin{array}{c}\text { Percentage } \\ \text { retained } \\ (\mathbf{W} / \mathbf{5 0 0 0}) * \mathbf{1 0 0}\end{array} & \begin{array}{c}\text { Cumulative } \\ \text { percentage } \\ \text { retained, C }\end{array} & \begin{array}{c}\text { Percentage } \\ \text { finer(100-C) }\end{array} \\ 1 & 80 & - & - & - & - \\ 2 & 63 & - & - & - & - \\ 3 & 50 & - & - & - & - \\ 4 & 40 & - & - & - & - \\ 5 & 31.5 & - & - & - & - \\ 6 & 25 & - & - & - & - \\ 7 & 20 & 20.0 & 0.4 & 0.4 & 99.6 \\ 8 & 16 & 1587.0 & 31.74 & 32.14 & 67.86 \\ 9 & 12.5 & 989.5 & 19.79 & 51.93 & 48.07 \\ 10 & 10 & 787.5 & 15.75 & 67.68 & 32.32 \\ 11 & 6.3 & 845.0 & 16.9 & 84.58 & 15.42 \\ 12 & 4.75 & 768.5 & 15.37 & 99.95 & 0.05 \\ \text { Total } & & & \sum \mathbf{n =} \mathbf{3 3 6 . 6 8} & \end{array}$

\subsection{Tests On Fine Aggregate}

The different tests conducted on Natural sand and the results are tabulated as shown in the table below. The tests are conducted as per IS:-2386(part 1, 3)-1963 (7).

Sieve analysis: The results of sieve analysis conducted on River sand is as shown in the Table 3.3.1.

\begin{tabular}{ccccc}
\hline IS sieve no & $\begin{array}{c}\text { Wt of } \\
\text { sample }\end{array}$ & $\begin{array}{c}\text { \%Wt } \\
\text { retained }\end{array}$ & Cumulative \% wt C & \% fine $\mathbf{N}=(\mathbf{1 0 0}-\mathbf{C})$ \\
4.75 & 12 & 1.2 & 1.2 & 98.8 \\
2.36 & 30 & 3 & 4.2 & 95.8 \\
1.18 & 112 & 11.2 & 15.4 & 84.6 \\
$600 \mu$ & 349 & 34.9 & 50.3 & 49.7 \\
$300 \mu$ & 377 & 37.7 & 88.0 & 12 \\
$150 \mu$ & 103 & 10.3 & 98.3 & 1.7 \\
Pan & 00 & 00 & 00 & 00 \\
Total & $\sum \mathbf{n}=$ & $\mathbf{2 5 7 . 4}$ &
\end{tabular}




\subsection{Tests on Rubber Aggregate}

The different tests conducted on rubber aggregate and the results obtained are as follows. The tests are conducted as per IS: 2386(partl,3)-1963(7).

\begin{tabular}{lll}
\hline Serial No & Tests Conducted & Results \\
1 & Water absorption & $0.2 \%$ \\
2. & Specific Gravity & 1.12 \\
\hline
\end{tabular}

\section{Experimental Programming}

\subsection{Tests on Fresh Concrete}

\subsubsection{Slump Test}

Unsupported fresh concrete flows to the sides and a sinking in height takes place. This vertical settlement is known as slump. Slump is a measure indicating the consistency or workability of cement concrete. It gives an idea of water content needed for concrete to be used for different works. The concrete is said to be workable if it can be easily mixed and placed, compacted and finished.

The mould for the slump test is in the form of a frustum of a cone, with internal diameter as: the top diameter $100 \mathrm{~mm}$, bottom diameter $200 \mathrm{~mm}$ and the height $300 \mathrm{~mm}$.It stands on a plane non porous surface. The tamping rod is $16 \mathrm{~mm}$ in diameter, $0.6 \mathrm{~m}$ long and is bullet pointed at the lower end. Concrete is filled in mould as three layers using tamper rod by tampering 25 times on each layer. The highest readings are taken by measuring on ruler, as the slump cone is lifted up vertically suddenly without any disturbance.

Here the slump test is conducted for control concrete and rubberized concrete by partially replacing coarse aggregate by different percentage of rubber aggregates. The classification of concrete based on slump values is listed in the table.

Results of slump test

\begin{tabular}{cccc}
\hline Serial no & $\begin{array}{c}\text { Grades of } \\
\text { concrete }\end{array}$ & $\begin{array}{c}\text { Replacement } \\
\text { of rubber } \\
\text { aggregates in } \%\end{array}$ & $\begin{array}{c}\text { Slump } \\
\text { in mm }\end{array}$ \\
1 & & 0 & 45 \\
2 & M15 & 10 & 30 \\
3 & & 25 & 15 \\
4 & & 50 & 10 \\
1 & & 0 & 60 \\
2 & M30 & 10 & 40 \\
3 & & 25 & 25 \\
4 & & 50 & 12 \\
\hline
\end{tabular}




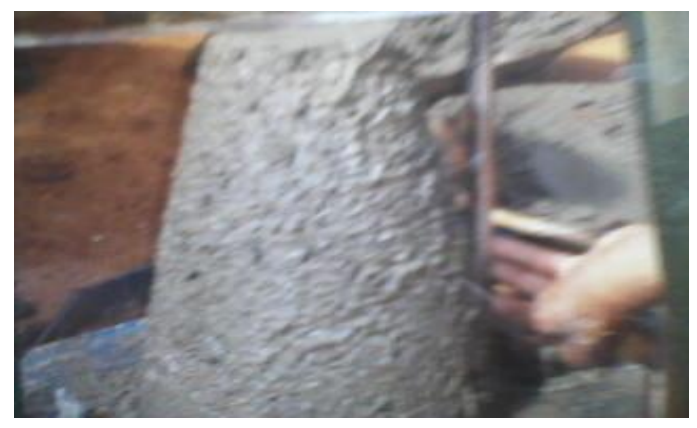

\subsubsection{Compaction Factor Test}

The workability property of concrete can be measured by compaction factor. Aggregates not exceeding $40 \mathrm{~mm}$ are considered as nominal sized aggregates must be used as aggregates.

The apparatus consists of a column supporting two funnel-shaped hoppers mounted above each other. Each of the hoppers is fitted with a quick-release trap door. The upper hopper has internal dimensions as: top diameter $250 \mathrm{~mm}$, bottom diameter $125 \mathrm{~mm}$ and height $225 \mathrm{~mm}$. The lower hopper has internal dimensions as: top diameter $225 \mathrm{~mm}$, bottom diameter $125 \mathrm{~mm}$ and height $225 \mathrm{~mm}$. The cylinder has internal dimensions as:150mm diameter and $300 \mathrm{~mm}$ height. The distance between bottom of upper hopper and top of lower hopper and bottom lower hopper and top of cylinder are $200 \mathrm{~mm}$ in each case.

The top hopper is filled with the fresh concrete sample. The trap door of the upper hopper is then opened to allow the concrete to fall into the lower one. The trap door of the lower hopper is then opened to allow the concrete to fall into the cylinder. Surplus concrete is removed and the cylinder is weighed and recorded as mass mp. After weighing, the cylinder is compacted and fresh concrete is added to ensure that the cylinder has been filled flush with its top edge by the fully compacted concrete. The fully compacted concrete is weighed and recorded as the mass mf. The Compacting Factor is given as follows:

Compacting factor, $\mathrm{CF}=\mathrm{mp} / \mathrm{mf}$

The results of slump and compaction factor test are tabulated as shown in the tables.

\begin{tabular}{ccccc}
\hline Serial no & $\begin{array}{c}\text { Grades of } \\
\text { concrete }\end{array}$ & $\begin{array}{c}\text { Replacement } \\
\text { of rubber aggregates in } \\
\text { \% }\end{array}$ & $\begin{array}{c}\text { Compacting } \\
\text { factor }\end{array}$ & $\begin{array}{c}\text { Degree of } \\
\text { workability }\end{array}$ \\
1 & & 0 & 0.79 & Low \\
2 & \multirow{2}{*}{ M15 } & 25 & 0.78 & Very low \\
3 & & 50 & 0.76 & Very low \\
4 & & 0 & 0.73 & Very low \\
1 & & 10 & 0.9 & Medium \\
2 & \multirow{2}{*}{ M30 } & 25 & 0.89 & Medium \\
3 & & 50 & 0.87 & Medium \\
4 & & & 0.86 & Medium \\
\hline
\end{tabular}




\subsection{Tests on Hardened Concrete}

\subsubsection{Compressive Strength of Concrete}

One of the important properties of concrete is its strength in compression. The strength in compression has a definite relationship with all the other properties of concrete i.e. these properties are improved with the improvement in compressive strength. The size of the mould is usually $(150 * 150 * 150) \mathrm{mm}$. Concrete cubes are tested for 7 days and 28 days strength as per IS: 516-1959 (5) procedure is followed for testing of concrete cubes. Rate of application Compressive load is $140 \mathrm{Kg} / \mathrm{cm}^{2} / \mathrm{min}$ and is tested in a universal testing machine as shown in the figure below.

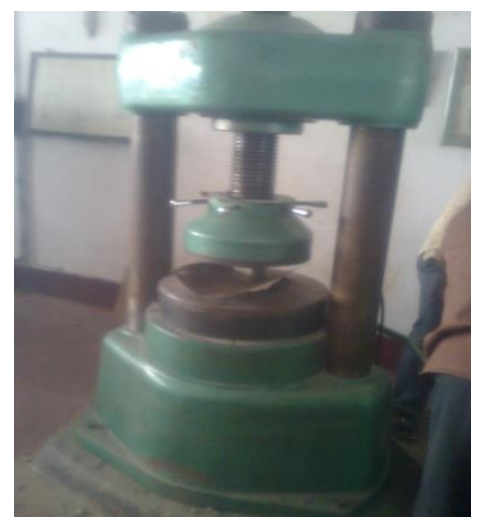

The compressive strength of concrete cube is given by, Cube strength $=$ average load $/$ area of cross section Results of compressive strength

For M30 grade of concrete

\begin{tabular}{ccccc}
\hline $\begin{array}{c}\text { Sl. } \\
\text { No }\end{array}$ & $\begin{array}{c}\text { Grade of } \\
\text { concrete }\end{array}$ & $\begin{array}{c}\text { Replacement by rubber } \\
\text { aggregates in \% }\end{array}$ & \multicolumn{2}{c}{$\begin{array}{c}\text { Compressive } \\
\text { strength in N / mm }\end{array}$} \\
& & & Avg 7 day strength & Avg 28 day strength \\
& & 10 & 23.40 & 32.02 \\
1 & \multirow{3}{*}{ M15 } & 25 & 15.00 & 26.88 \\
& & 50 & 10.40 & 24.10 \\
& & 0 & 28.16 & 16.53 \\
& & 10 & 24.53 & 46.26 \\
2 & M30 & 25 & 21.13 & 40.60 \\
& & 50 & 13.13 & 29.80 \\
& & & & 18.90 \\
\hline
\end{tabular}

As results shows gradual decrement of compressive strength by increment in proportion of rubber added to concrete respectively. This is observed that rubber used concrete doesn't exhibit any type of typical compressive failure behavior. As the bonding and holding properties of concrete increases due to presence of rubber pieces as aggregates. 


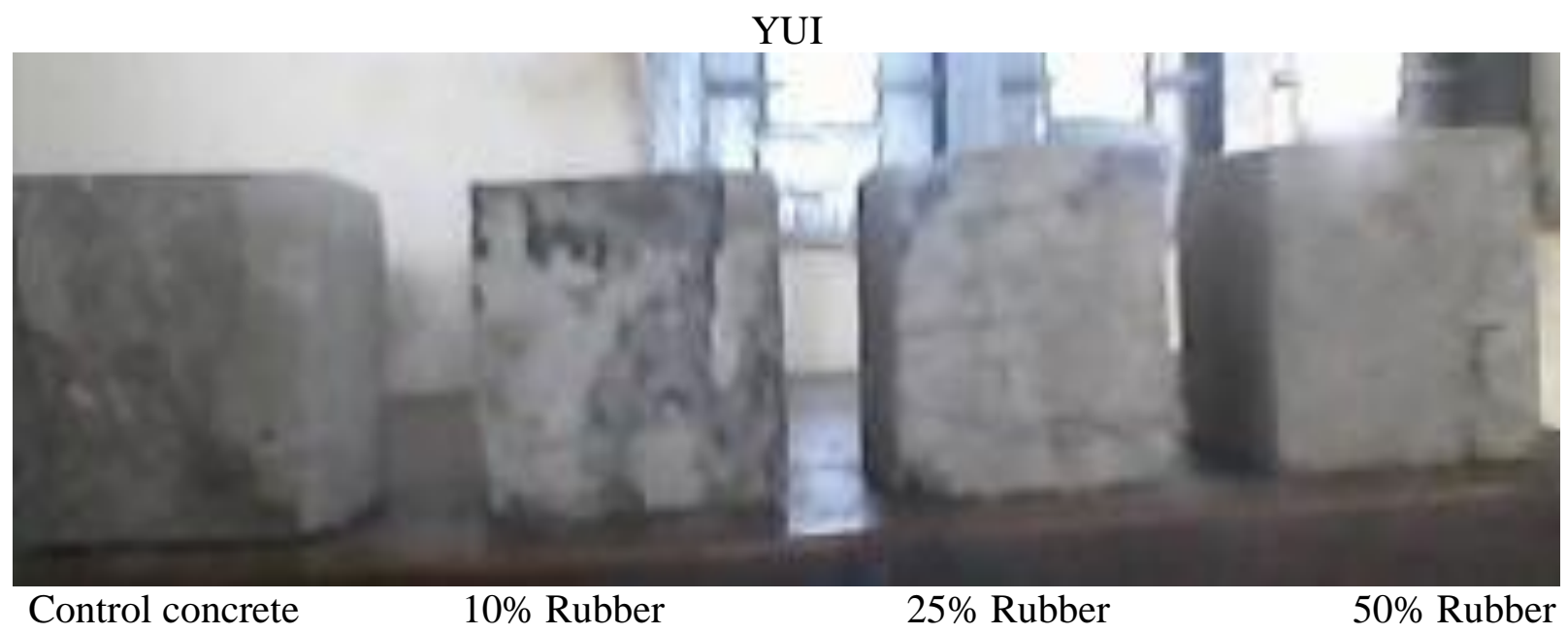

\subsubsection{Unit Weight}

As table 4.4 shows the decrement in unit weight of rubberized concrete as the specific gravity of rubber chips used are low. By using rubber clip volume upto50\% the unit weight of concrete is reduced to $10 \%$.

Here the unit weight of control concrete is compared with the rubberized concrete by considering the unit weight of cubical specimen.

\begin{tabular}{ccccc}
\hline Type & Weight in kg & Volume $\mathbf{~ m 3}$ & Unit wt kg/m3 & \% Reduction \\
Control concrete & 8.1 & $(0.15) 3$ & 2400 & 0 \\
$\mathbf{1 0 \%}$ rubber & 7.93 & $(0.15) 3$ & 2350 & 2.08 \\
$\mathbf{2 5 \%}$ rubber & 7.60 & $(0.15) 3$ & 2251 & 6.25 \\
$\mathbf{5 0 \%}$ rubber & 6.58 & $(0.15) 3$ & 1950 & 18.75 \\
\hline
\end{tabular}

\subsubsection{Split Tensile Strength}

As concrete is well known for taking compressive strength, they are poor in withstanding tensile loads, concrete is non-brittle material too. Hence to withstand tensile strength concrete will be reinforced by steel rods and grits which even gives additional support to concrete.. The split tensile strengths of concrete specimens were determined after 14 days 28 days of standard curing. The tests were carried out by splitting the cylinders in the machine used for compressive testing .The specimen is made and tested in accordance with IS 515-1959. The testing machine is fitted with an extra bearing bar to distribute the load along the full length of the cylinder. Hardboard strips, $15 \mathrm{~mm}$ wide and $4 \mathrm{~mm}$ thick is inserted between the cylinder and the testing machine top and bottom bearing surfaces. From the maximum applied load at failure the splitting tensile strength is calculated as follows: 
Results of split tensile strength

\begin{tabular}{|c|c|c|c|c|}
\hline $\begin{array}{l}\text { Sl } \\
\text { No }\end{array}$ & \multirow[t]{2}{*}{$\begin{array}{l}\text { Grade of } \\
\text { concrete }\end{array}$} & \multirow[t]{2}{*}{$\begin{array}{l}\text { Replacement by } \\
\text { rubber aggregates } \\
\text { in \% }\end{array}$} & \multicolumn{2}{|c|}{$\begin{array}{c}\text { Tensile } \\
\text { strength in } \mathrm{N} / \mathrm{mm}^{2}\end{array}$} \\
\hline 1 & & & $\begin{array}{c}\text { Avg } 14 \text { davs strength } \\
1.59\end{array}$ & $\begin{array}{c}\text { Avg 28davs strength } \\
2.37\end{array}$ \\
\hline 2 & \multirow{4}{*}{ M15 } & 10 & 1.49 & 1.83 \\
\hline 3 & & 25 & 1.41 & 1.77 \\
\hline 4 & & 50 & 0.96 & 1.27 \\
\hline 5 & & 0 & 2.82 & 3.06 \\
\hline 6 & \multirow{3}{*}{ M30 } & 10 & 2.65 & 2.80 \\
\hline 7 & & 25 & 2.48 & 2.60 \\
\hline 8 & & 50 & 1.34 & 1.69 \\
\hline
\end{tabular}

The figure below shows the splitting of cylindrical specimen after applying the load

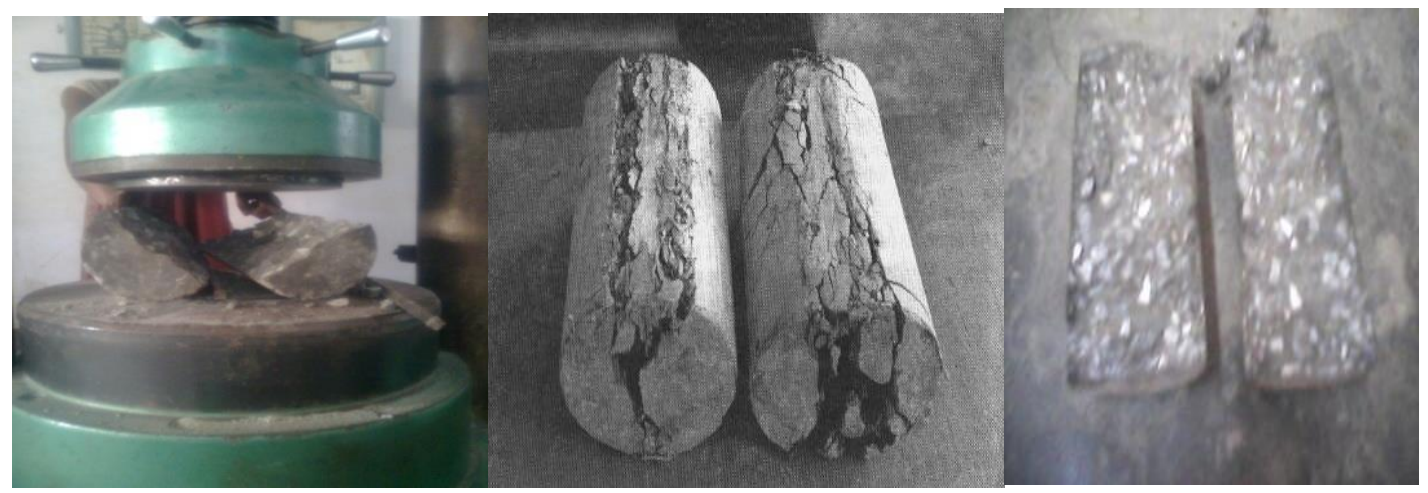

Control Concrete specimen under Utm Rubberized Concrete

Similar to compressive strength shown above, the tensile properties of concrete also gradually reduce by increment in the volume percentage increment of rubber as coarse aggregates. . The splitting tensile strength test samples for control and rubberised concrete are shown after testing in Figure 5.2.2.5 and 5.2.2.6. It is clearly observed from diagram as the tensile strength exerted on mould made split into two halves longitudinally, this shows clearly that by using rubber as coarse aggregates reduces the properties of concrete to withstand the tensile loads.

\subsection{Flexural Strength}

The flexural strength expressed in terms of modulus of rupture is defined as the maximum tensile stress in the concrete at rupture in flexure test. The concrete test specimen for flexural strength is a prism of cross section $(150 * 150 * 700) \mathrm{mm}$. The flexural strengths of concrete specimens were determined after 28 days of standard curing. The beams were tested in the laboratory using an Avery Universal Machine Type 1700 , which has a capacity of $500 \mathrm{KN}$. The load was applied at a rate of $0.16 \mathrm{~N} / \mathrm{mm} 2$ per second. In this test, a load is applied through two rollers at the third points of the span until the specimen breaks. Under these conditions, the lower surface of the beam is in tension. The beam fails by the growth of a crack from the tensile zone through the 
concrete. Using standard beam formulae, the failure stress can be calculated from the beam dimensions and the failure load.

\subsection{Flexural Strength}

Concrete filled in mould measuring $150 * 150 * 700 \mathrm{~mm}$, then it will be placed under universal testing machine to exert the flexural strength. The specimen cured for 28days for hardening of concrete block, as the concrete attains up to $90-95 \%$ of its hardness. The load is applied on two rollers as three point loads until the specimen cracks which is clearly visible to the reader, the readings of flexural strength of concrete musty be taken carefully as MPa units.

The loading arrangement with symmetric loads $(\mathrm{P})$ at $1 / 3$ points produces a pure bending zone with constant bending moment and zero shears in the middle third of the span. If the fracture occurs within the middle third of the span, the flexural strength is given by;

The flexural strength test was carried out by replacing coarse aggregate by optimum rubber content of $25 \%$. The arrangement for flexure testing is shown below and the beam before testing and after testing is shown by the below.

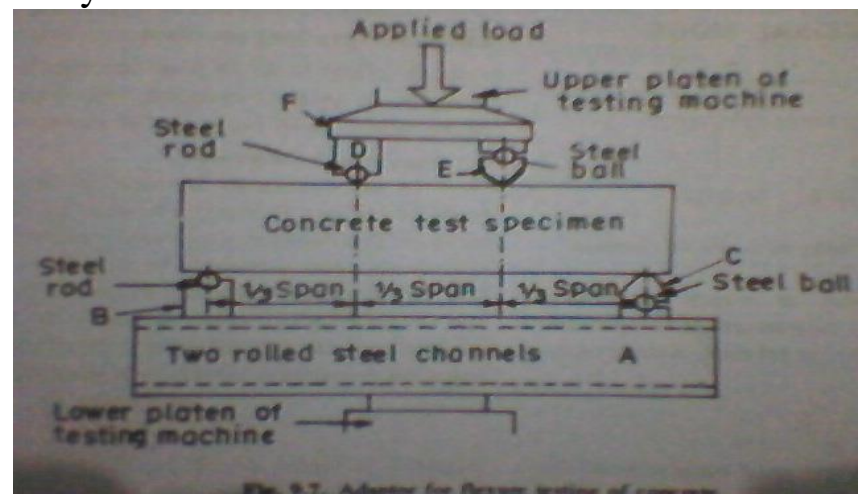

Arrangement for Flexure Test Of Concrete

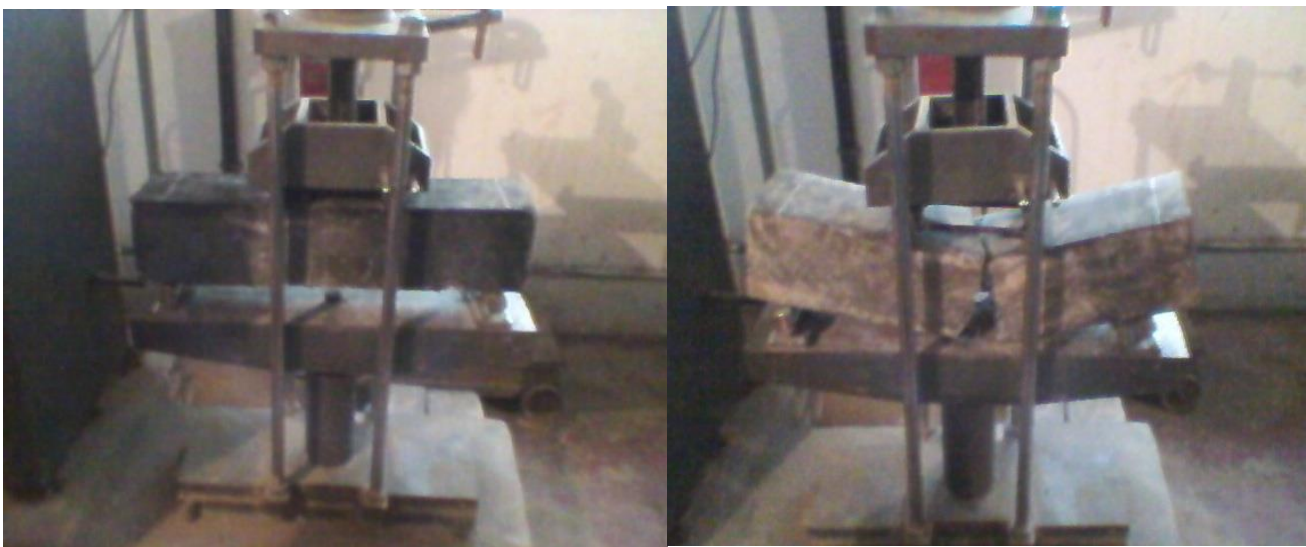

Beam Before Testing Beam after Testing

While testing the beam, it is observed that for the control concrete the fracture occurs exactly at the centre of the beam that is within middle third span; hence the flexural strength is calculated by using the first formula. Whereas for the beam with rubber aggregates the fracture occurs 
outside the middle third span and hence the flexural strength is calculated by using the second formula.

The results show that the flexural strength increased compare to the control mix for rubber aggregate contents of $25 \%$.

\begin{tabular}{cccc}
\hline SI No & Grade of concrete & $\begin{array}{c}\text { Replacement by rubber } \\
\text { aggregates in \% }\end{array}$ & $\begin{array}{c}\text { Flexural strength in } \mathbf{~} \\
/ \mathbf{m m}^{2}(\mathbf{2 8} \text { days })\end{array}$ \\
1 & \multirow{2}{*}{ M30 } & 0 & 4.14 \\
2 & & 25 & 6.20 \\
\hline
\end{tabular}

\section{Conclusions}

The above results conducted on concrete samples which are hardened and cured for 28days shows that the compressive strength, slip tensile test and flexural strength of concrete gradually reduces by the increment in volume proportion of rubber pieces added to concrete obtained by tyre waste rubber clips.

The surface tension of rubber chips used are smooth, hence by utilizing this as coarse aggregate will reduces bond strength between the concrete material. As rubber is elastic material this creates a serious problem, as this has no specific size and shape his makes the concrete material non rigid even after hardening of concrete for certain time.

Although using of rubber won't play any role in increment in concrete properties, but this may be used to increase the volume of concrete as the actual course aggregate materials such as stones and other building material volume can be reduced. Even by utilization of rubber as coarse aggregate the unit weight of concrete reduces. Utilizing the rubber as course aggregate makes an opportunity to reuse, recycling of rubber which is hazardous to dispose or burn in environment.

Using rubber as coarse aggregate will reduce the economy of construction as rubber is waste material.

\section{References}

[1] Gowreesh, S., Sreenivasalu Reddy, N. and Yogananda Murthy, NV. Convective Heat Transfer Analysis of a Aero Gas Turbine Blade Using Ansys, International Journal of Mechanics and Solids. 4, 2009, 39-46.

[2] B. Deepanraj, P. Lawrence, G. Sankaranarayanan, Theoretical analysis of gas turbine blade by Finite element method, Scientific World, Vol. 9, No. 9, July 2011, 29-33.

[3] Gurrappa, I. V. S. Yashwanth, A. K. Gogia, The Behaviour of Superalloys in Marine Gas Turbine Engine Conditions, Journal of Surface Engineered Materials and Advanced Technology, 1, 2011, 144-149.

[4] Brooks CR. Heat treatment, structure and properties of nonferrous alloys. New York: ASM; 1984, 139-228. 
[5] Huda Z. Development of heat-treatment process for P/M superalloys for turbine blades. Mater 28(5), Des 2007; 1664-7.

[6] Boyce MP., The gas turbine handbook. 2nd ed. Houston, Texas: Gulf Professional Publishing; 2002, 411.

*Corresponding author.

E-mail address: raghudinakar@ gmail.com 